\title{
The relationship between social support and self-care behavior in patients with diabetes mellitus
}

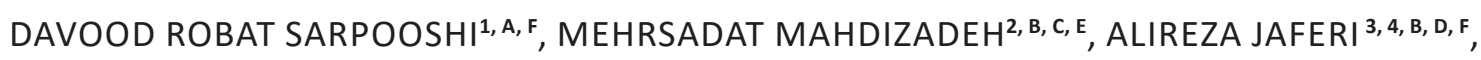 \\ HAMID ROBATSARPOOSHI ${ }^{5, \mathrm{~B}, \mathrm{~F}}$, MOHAMMAD HADDADI ${ }^{5, \mathrm{D}, \mathrm{E}}$, NOOSHIN PEYMAN ${ }^{6,7, \mathrm{~A}, \mathrm{E}, \mathrm{F}}$ \\ ORCID ID: 0000-0003-2942-7756
}

\author{
${ }^{1}$ Student Research Committee, Mashhad University of Medical Sciences, Mashhad, Iran \\ ${ }^{2}$ Department of Health Education and Health Promotion, Social Determinants of Health Research Center, School \\ of Health, Mashhad University of Medical Sciences, Mashhad, Iran. \\ ${ }^{3}$ Social Determinants of Health Research Center, Gonabad University of Medical Sciences, Gonabad, Iran \\ ${ }^{4}$ Department of Health Education and Health Promotion, Faculty of Health, Gonabad University of Medical \\ Sciences, Gonabad, Iran \\ ${ }^{5}$ Faculty of Nursing, Sabzevar University of Medical Sciences, Sabzevar, Iran \\ ${ }^{6}$ Social Determinants of Health Research Center, Mashhad University of Medical Sciences, Mashhad, Iran \\ ${ }^{7}$ Department of Health Education and Health Promotion, Faculty of Health, Mashhad University of Medical \\ Sciences, Mashhad, Iran
}

A - Study Design, B - Data Collection, C - Statistical Analysis, D - Data Interpretation, E - Manuscript Preparation, F - Literature Search, G - Funds Collection

Summary Background. Diabetes mellitus (DM) is currently not curable but controllable and must be managed. Family support has been stated as a vital component in successful control of DM and the strongest determinant of adherence to diet therapy in DM patients.

Objectives. The study was conducted to examine social support and its relationship with practicing self-care behavior in patients with DM in Mashhad.

Material and methods. In this analytical cross-sectional study, 400 patients with DM were selected over two months from DM clinics in Mashhad using the census sampling method. Data was collected using demographic information, social support and self-care questionnaires. Data analysis was done in SPSS 21 using the statistical Spearman's rank correlation coefficient, $t$-Test and analysis of variance.

Results. The results indicated a significant relationship between the social support and self-care behavior of DM patients $(p=0.031)$. This means that social support is an effective factor in practicing self-care behaviors. Moreover, the results indicated that most of the samples had moderate social support and self-care behavior. There was a significant relationship between self-care and health literacy in the study $(p=0.026)$ : individuals with higher health literacy had better self-care. There was a significant relationship between education and monthly income with self-care behaviors and support of the individuals $(p=0.001)$.

Conclusions. Individuals with better social support have adhered to DM self-care behaviors, and adhering to self-care behaviors has led to blood sugar control and prevention of adverse effects. Furthermore, patient support and participation in self-care enable them to take the next step for better management of the disease and prevention of future adverse effects.

Key words: social support, diabetes mellitus, self care.

Sarpooshi DR, Mahdizadeh M, Jaferi A, Robatsarpooshi H, Haddadi M, Peyman N. The relationship between social support and self-care behavior in patients with diabetes mellitus. Fam Med Prim Care Rev 2021; 23(2): 227-231, doi: https://doi.org/10.5114/ fmpcr.2021.105932.

\section{Background}

Over recent decades, the prevalence of DM in the world has increased annually by about $6 \%$, with the world facing a DM epidemic. According to a prediction by the World Health Organization (WHO), the number of 20-year-old and older adults with DM is expected to reach 300 million by 2025 [1]. Additionally, 150 million people suffer from DM in the world, $15 \%$ of whom suffer from diabetic foot ulcers [2]. The prevalence of DM is estimated to be $7.7 \%$ in Iran's 25-64-year-old population [3]. According to studies available, the most significant cause of mortality in DM patients and chronic adverse effects of DM is lack of self-care [4]. Self-care in DM is considered as one of the most basic solutions for controlling the disease and prevents $85 \%$ of these problems and can reduce the readmission of these patients [5].
DM is currently not curable but controllable and must be managed. Type 2 DM control involves the implementation of a multidimensional self-care program that usually involves blood glucose determination, diet, exercise, medication, body weight control and training.

Such self-care activities may be very demanding and usually involve major changes in lifestyle, thus many patients do not fully comply with medical recommendations despite their awareness of the adverse effects of the disease, leading to the possibility of the spread of complications related to DM increasing. Various studies indicate that social support has positive effects on different aspects of self-care activities. This concept is defined as social support being "the facilities others provide for the individual" [6]. Social support has been defined as the feeling of acceptance by others [7], as well as the degree of having love, companionship and the attention of family members, 
friends and others [8]. It can affect all family members, thus family support is considered as a vital component in successful control of DM and the strongest determinant of adherence to diet therapy in Type 2 DM patients [9].

Social support affects DM control through two major processes: a) social-support direct effect through health-related behaviors, such as enjoining healthy behaviors, and b) the moderating effect of social support that helps moderate the effects of acute and chronic stress on health, as well as increased adaptation to DM [6]. Previous studies have shown a relationship between social support as an environmental and psychological factor and self-care behaviors [10]. Moreover, low social support from friends and others can affect the health status situation, and high levels of social support are associated with higher physical and psychological levels [11].

\section{Objectives}

Given the points stated and the status of social support in practicing self-care behaviors in DM patients, the study was conducted to examine social support and its relationship with practicing self-care behaviors in patients with DM in Mashhad.

\section{Material and methods}

This was an analytical cross-sectional study carried out on DM patients over 30 years of age in Mashhad. Inclusion criteria were the willingness to participate in the study, definitive diagnosis of Type 2 DM based on laboratory evidence recorded in inpatient health records in healthcare centers, not having any chronic illnesses and DM adverse effects, age 30 and over, Iranian nationality and at least 6 months have passed from the disease diagnoses. The exclusion criteria were withdrawal from the study, suffering DM adverse effects, patients with gestational DM and any medical problems preventing self-care behaviors (exercise and regular physical activity). Random sampling method was available. The sampling was random convenience sampling method. Given the sample size of 400 , the individuals took part in the study after becoming aware of the project goals.

The following tools were used for data collection: 1. Demographic information questionnaire with 11 questions, such as age, gender, education level, job type, duration of illness, etc. and 2. Social Support Questionnaire (SSQ). This scale was developed in 1986 by Wux, Riedel and Stewart using the Structure Analysis Method and has 23 questions in three subscales: family support, 8 items; friend support, 7 items; and others' support, 8 items. The answering method was yes or no, where the scores were divided into three groups: poor, average and good. Individuals with scores below $50 \%$ were placed in the poor group, between $50-75 \%$ in the average, and above $75 \%$ in the good group. The validity and reliability of this questionnaire were reported on in previous studies in Iran [12]. The self-care behavior construct was based on the short form of the self-care behaviors questionnaire by Toobert and Glasgow (Summary of Diabetes Self-Care Activities (SDSCA)) [13], the validity and reliability of which have been proven in many studies in Iran, such as the study by Hatamloo et al. [14]. The questionnaire has 12 questions and measures self-care behavior in 4 domains (nutrition, physical activity, blood sugar monitoring and blood sugar consumption) over the past 2 days.

The scores in the questionnaire ranged from zero to two. If a patient selects all days of the week in answering a question like "How many days of exercise or physical activity did you have in the past week?", he gets the highest score (i.e. 2). If he had not done so in the past week, he would receive zero. This was done for all 4 self-care behaviors, including diet, physical activity or exercise, using an anti-DM drug and blood glucose self-control behavior. Higher scores show more favorable self-care behaviors over the past week. One has to note that the researcher completed the questionnaires as a structured interview with participants in 15-23 minutes.

Data was analyzed in SPSS 21 using Spearman's rank correlation coefficient, independent $t$-Test and analysis of variance. The significance level in all tests was considered as less than 0.05 .

\section{Ethical approval and consent to participate}

All procedures performed in the study followed the ethical standards of the institutional and/or national research committee and those of the 1964 Helsinki declaration. All project participants were informed of the study objectives and completed a written consent form and were assured of the confidentiality of their personal information.

\section{Results}

The age of the patients in the study ranged from 33 to 71 years, with a mean age of $53.8 \pm 11.9$. A majority of the participants in the study had Type 2 DM (89\%) and were female (59\%), married (69\%), with high school education (35\%) and $73 \%$ of the participants had a family history of DM, and the source of health information on DM for $76 \%$ of the individuals was physicians and clinic staff.

Thus, the comparison of mean self-care scores based on individual characteristics of the patients and disease specifications did not show any significant differences in various age groups and the mean score of self-care behaviors ( $p=N S)$.

The results showed that the mean self-care score had a significant relationship with educational level, economic status and regular physician visits, thus the mean self-care score was significantly higher in patients with university education and higher economic status and in those who regularly visited a physician compared to the others (Table 1).

\begin{tabular}{|c|c|c|c|c|}
\hline \multirow[t]{2}{*}{ Specifications } & \multirow[t]{2}{*}{ Number } & \multirow[t]{2}{*}{ Percent } & Self-care score & \multirow[t]{2}{*}{ Test result: } \\
\hline & & & Mean \pm SD & \\
\hline $\begin{array}{c}\text { Age (years) } \\
\quad 30-40 \\
40-50 \\
50-60 \\
\leq 60 \\
\end{array}$ & $\begin{array}{l}103 \\
125 \\
172 \\
40 \\
\end{array}$ & $\begin{array}{l}25 \\
31 \\
43 \\
10 \\
\end{array}$ & \begin{tabular}{|l|}
$31.9 \pm 13.1$ \\
$34.6 \pm 9.7$ \\
$28.1 \pm 12.7$ \\
$26.9 \pm 7.4$ \\
\end{tabular} & $\begin{array}{l}f=0.3 \\
p=\text { NS }\end{array}$ \\
\hline $\begin{array}{l}\text { Gender } \\
\text { female } \\
\text { male }\end{array}$ & $\begin{array}{l}236 \\
164 \\
\end{array}$ & $\begin{array}{l}59 \\
41 \\
\end{array}$ & $\begin{array}{l}32.4 \pm 12.8 \\
28.6 \pm 8.6\end{array}$ & $\begin{array}{l}2 X=2.4 \\
p=\mathrm{NS}\end{array}$ \\
\hline $\begin{array}{l}\text { Marital status } \\
\text { single } \\
\text { married } \\
\text { widowed and divorced }\end{array}$ & $\begin{array}{l}35 \\
278 \\
87\end{array}$ & $\begin{array}{l}8 \\
69 \\
21\end{array}$ & $\begin{array}{l}34.9 \pm 11.8 \\
30.6 \pm 12.2 \\
29.4 \pm 7.9\end{array}$ & $\begin{array}{l}2 X=0.4 \\
p=N S\end{array}$ \\
\hline
\end{tabular}




\begin{tabular}{|c|c|c|c|c|}
\hline \multirow[t]{2}{*}{ Specifications } & \multirow[t]{2}{*}{ Number } & \multirow[t]{2}{*}{ Percent } & \multirow{2}{*}{\begin{tabular}{|l} 
Self-care score \\
Mean \pm SD
\end{tabular}} & \multirow[t]{2}{*}{ Test result } \\
\hline & & & & \\
\hline $\begin{array}{l}\text { Education } \\
\text { elementary } \\
\text { guidance } \\
\text { secondary } \\
\text { academic }\end{array}$ & $\begin{array}{l}91 \\
94 \\
140 \\
75\end{array}$ & $\begin{array}{l}22 \\
23 \\
35 \\
19\end{array}$ & $\begin{array}{l}28.7 \pm 12.7 \\
31.0 \pm 10.4 \\
30.1 \pm 13.1 \\
32.9 \pm 9.4\end{array}$ & $\begin{array}{l}F=4.3 \\
0.03\end{array}$ \\
\hline $\begin{array}{l}\text { See your doctor regularly } \\
\text { yes } \\
\text { no }\end{array}$ & $\begin{array}{l}274 \\
126 \\
\end{array}$ & $\begin{array}{l}68 \\
32 \\
\end{array}$ & $\begin{array}{l}37.9 \pm 10.8 \\
31.3 \pm 12.5 \\
\end{array}$ & $\begin{array}{l}t=3.8 \\
0.001\end{array}$ \\
\hline $\begin{array}{l}\text { Family history of diabetes } \\
\text { yes } \\
\text { no }\end{array}$ & $\begin{array}{l}293 \\
107 \\
\end{array}$ & $\begin{array}{l}73 \\
27 \\
\end{array}$ & \begin{tabular}{|l|l}
$35.7 \pm 11.2$ \\
$30.5 \pm 9.7$ \\
\end{tabular} & $\begin{array}{l}t=1.2 \\
p=\mathrm{NS}\end{array}$ \\
\hline $\begin{array}{l}\text { Economic situation } \\
\text { poor } \\
\text { medium } \\
\text { good } \\
\text { excellent }\end{array}$ & \begin{tabular}{|l|}
82 \\
218 \\
78 \\
22
\end{tabular} & $\begin{array}{l}21 \\
55 \\
19 \\
5\end{array}$ & $\begin{array}{l}30.6 \pm 13.2 \\
31.4 \pm 12.3 \\
31.7 \pm 9.2 \\
34.7 \pm 10.6\end{array}$ & $\begin{array}{l}2 X=3.7 \\
0.04\end{array}$ \\
\hline
\end{tabular}

*Significance level was less than 0.05 in all subjects.

\begin{tabular}{|c|c|c|c|c|c|}
\hline Social support & Age & Marital status & Education & $\begin{array}{l}\text { Family history of } \\
\text { diabetes }\end{array}$ & Economic situation \\
\hline Correlation coefficient & -3.681 & 0.385 & 4.973 & 0.473 & 2.690 \\
\hline Significance level & $p<0.005$ & 0.812 & $p<0.005$ & 0.721 & 0.048 \\
\hline
\end{tabular}

\begin{tabular}{|l|l|l|l|l|l|}
\hline \multicolumn{3}{|l|}{ Table 3. Distribution of absolute and relative frequency among researchers by social support and self-care behavior scores } \\
\cline { 3 - 6 } & Mean \pm SD & Poor & Medium & Good & Excellent \\
\cline { 2 - 6 } & & Number (percent) & Number (percent) & Number (percent) & Number (percent) \\
\hline Social support & $17.16 \pm 4.07$ & $52(13)$ & $185(46.2)$ & $163(40.7)$ & - \\
\hline Self-care behavior & $34.85 \pm 12.19$ & $137(34.2)$ & $166(41.5)$ & $83(20.7)$ & $14(3.5)$ \\
\hline
\end{tabular}

\begin{tabular}{|l|l|l|}
\hline \multicolumn{3}{|l|}{ Table 4. Correlation coefficient between social support and self-care behavior } \\
\hline \multirow{2}{*}{ Dimensions of self-care } & Social support & Significance level \\
\cline { 2 - 3 } & Correlation coefficient & $p<0.001$ \\
\hline Healthy diet & 0.758 & $p<0.001$ \\
\hline Physical activity & 0.893 & $p<0.001$ \\
\hline Blood sugar monitoring & 0.680 & $p<0.001$ \\
\hline Proper use of medicines & 0.737 & \\
\hline
\end{tabular}

There were no significant relationships between gender, marital status and family history of DM and self-care behaviors in the study ( $p=$ NS) (Table 2 ).

The results showed a significant and inverse relationship between social support and the age of the subjects $(p<0.005)$ : social support decreased with an increase in age. However, there was a significant and direct relationship with the level of education. No significant relationships were found between social support and marital status, family history of DM and economic status.

In the examination of social support, the results showed that $40.7 \%$ of the samples had good social support, $46.2 \%$ average social support, and the rest had poor social support. The mean score of overall social support was 17.16, determined by desirability level, which shows that the mean score of social support in these patients was average, and the majority of samples had moderate to poor self-care (Table 3 ).

In the descriptive statistics, the mean total score of self-care was 34.85 , with a standard deviation of 12.19 , which indicates that the score of self-care behavior in these patients is average, with the majority of samples having average and poor self-care based on desirability level.
Spearman's rank correlation coefficient between social support and the domains of diabetes self-care behaviors (healthy eating behaviors, physical activity, blood glucose monitorin, and proper medication use) was significantly and directly correlated (Table 4).

\section{Discussion}

The study was conducted to examine the relationship between social support and self-care behaviors in patients with DM admitted to public and private centers in Mashhad.

In this study, the self-care score was close to $34.85 \pm 12.19$ and showed at least moderate levels of self-care. This finding was in agreement with previous studies conducted by Anbari et al. [15], Kordi et al. [16] and Moeini et al. [17].

Moreover, the study by Jordan et al. on self-care behaviors in DM patients in America showed that patients' self-care status was moderately favorable [18]. However, in the study by Mazlom et al. [19] and Parham et al. [20], the self-care of the studied samples was reported as poor and undesirable. It seems that the differences in patients' self-care status in various studies are 
due to various elements, such as differences in social support of the samples examined, differences in self-care education programs for DM patients or differences in knowledge and attitude towards self-care behavior.

In this study, perceived social support was close to $46 \%$ of the participants and showed at least moderate levels of social support. This finding was in agreement with the previous studies conducted by Cooper et al. [21] and Gillibrand and Stevenson [22].

In a study, Heidari indicated that social support in DM patients is not favorable [23], and Morovvati and Rouhani [24] reported that social support in DM patients was not desirable. These results are consistent with the findings of this study.

The results of various studies show that social support is one of the factors affecting health and self-care behaviors. Among the other positive results of social support are increased behavioral health, personal growth and competence and better adaptation to the illness [25].

The results showed a direct and significant relationship between self-care behavior and social support among DM patients, and thus patients with higher social support showed better selfcare behaviors. Therefore, social support, especially family support, can be a vital component in successful DM control. Idalski Carcone et al. reported that social support plays a direct role in controlling and enhancing self-care behaviors in patients with DM [10]. Furthermore, the study by Zare Shahabadi et al. indicated a direct and significant relationship between perceived social support and self-care activities [26].

Aalto and Uutela showed a relationship between social support and adherence to diet therapy in DM patients as well [27]. Glasgow et al. reported that family support was the strongest determinant of adherence to diet therapy in patients with Type 2 DM [9]. Sharifirad et al. consider one of the hurdles to patients' adherence to diet compliance was lack of social and family support [28]. Those receiving higher levels of social support from their spouses and those around them will adhere better to self-care behaviors [29].

In examining family support, diet, and exercise among old Mexican-Americans with Type $2 \mathrm{DM}$, Wen et al. showed that adherence to diet and exercising improved with the increase in this support [30]. Marzilli and Cossege showed that family support has a significant effect on adherence to diet and exercise in DM patients [31], which is consistent with the results of the present study.

In his results, Klomegah showed that if family members, friends and relatives adhere to a healthy diet, adherence to a healthy diet would be easier for patients as well [32]. Lloyd et al. studied the psychosocial factors related to glycemic control. In their study, adherence to these recommendations increased with an increase in social support for adherence to self-care instructions [33]. These results are consistent with the findings of this study.

Furthermore, social support and self-care significantly decreased with increasing age and duration of diabetes. This result is similar to a study conducted by Robatsarpooshi et al. [34], and the finding in this study was in agreement with Mayberry's and Osborn study, which stated there was no association between perceived social support and education level [35].

If those around the DM patient use positive reinforcing behaviors (e.g. encouragement or companionship) to oblige the patients to adhere to their treatment plan, a better result is reached, and DM patients better adhere to their treatment plan. For instance, families have to bear in mind that preparing and eating foods suitable for diabetic patients can enable the patients to adhere better to their diet. DM can be controlled by observing self-care areas. Ultimately, one can deduce that those with better social support are more likely to adhere to DM self-care behaviors, and adhering to self-care behaviors leads to blood sugar-level control and prevention of adverse effects.

Among the limitations of the study, one can cite the long time needed to fill in the questionnaire by patients with low levels of education, for whom the research team deployed a dedicated questioner to convince them to complete the questionnaires patiently and accurately by explaining the purpose of the study.

\section{Conclusions}

The results showed a significant relationship between social support and DM self-care behavior. This means that social support is one of the factors affecting self-care behaviors. Additionally, social support in nursing care can enhance the health status of DM patients. Thus, patient support and participation in self-care enable them to build on their ability to better manage the disease and prevent its subsequent adverse effects. Ultimately, it is recommended that social support, the factors affecting it, self-management behaviors and the factors facilitating these behaviors in the family and community, along with the hurdles to social support and self-care behaviors, should be identified, and plans should be made for interventions to take effective steps to enhance the level of self-care behaviors and to value social support in the family and community.

Acknowledgments. The authors of the paper would like to express their gratitude to the heads and personnel of the public and private centers of Mashhad for their support and cooperation, along with all the participants who contributed to the project.

Source of funding: This work was funded from the authors' own resources.

Conflicts of interest: The authors declare no conflicts of interest.

\section{References}

1. Lantion-Ang LC. Epidemiology of diabetes mellitus in Western pacific region: focus on Philippines. Diabetes Res Clin Pract 2000; 50(Suppl. 2): S29-S34.

2. Searle A, Campbell R, Tallon D, et al. A qualitative approach to understanding the experience of ulceration and healing in the diabetic foot: patient and podiatrist persepctives. Wounds 2005; 17(1): 16-26.

3. Delavari A, Alikhani S, Nili S, et al. Quality of care of diabetes mellitus type II patients in Iran. Arch Iran Med 2009; 12(5): $492-495$.

4. Zareban I, Karimy M, Niknami S, et al. The effect of self-care education program on reducing $\mathrm{HbA}_{1 \mathrm{c}}$ levels in patients with type 2 diabetes. J Educ Health Promot 2014; 3: 123.

5. Spenceley SM, Williams BA. Self-care from the perspective of people living with diabetes. Can J Nurs Res 2006; 38(3): 124-145.

6. Montazeri A. Social determinants of health. Tehran: Jahad Daneshgahi; 2008.

7. Kanel R von. Psychosocial stress and cardiovascular risk: current opinion. Swiss Med Wkly 2012; 142: w13502.

8. Adams MH, Bowden AG, Humphrey DS, et al. Social support and health promotion lifestyles of rural women. Online Journal of Rural Nursing and Health Care 2017; 1(1): 43-65.

9. Glasgow RE, Wagner EH, Kaplan RM, et al. If diabetes is a public health problem, why not treat it as one? A population-based approach to chronic illness. Ann Behav Med 1999; 21(2): 159-170. 
10. Idalski Carcone A, Ellis DA, Weisz A, et al. Social support for diabetes illness management: supporting adolescents and caregivers. J Dev Behav Pediatr 2011; 32(8): 581-590.

11. Beattie S, Lebel S, Tay J. The influence of social support on hematopoietic stem cell transplantation survival: a systematic review of literature. PLOS ONE 2013; 8(4): e61586.

12. Vaux A, Riedel S, Stewart D. Modes of social support: the social support behaviors (SS-B) scale. Am J Community Psychol 1987; 15(2): 209-232.

13. Toobert DJ, Glasgow RE. Assessing diabetes self-management: the summary of diabetes self-care activities questionnaire. In: Bradley C, ed. Handbook of psychology and diabetes. Amsterdam: Harwood Academic Publishers; 1994: 351-375.

14. Hatamloo M, Babapour J, Poorsharifi H. Health locus of control and causal trends in predicting self-care roles of people with diabetes. J Tabriz Uni Psychiatry 2010; 5(19): 32-53.

15. Anbari K, Ghanadi K, Kaviani M, et al. The self-care and its related factors in diabetic patients of khorramabad city. Yafteh 2012; 14(4): 49-57.

16. Kordi M, Banaei M, Asgharipour N, et al. Prediction of self-care behaviors of women with gestational diabetes based on belief of person in own ability (self-efficacy). The Iranian Journal of Obstetrics, Gynecology and Infertility 2016; 19(13): 6-17.

17. Moeini B, Teimouri P. Haji Masoudi S, et al. Analysis of self-care behaviors and its related factors among diabetic patients. Qom Univ Med Sci J 2016; 10(4): 48-57.

18. Nouhjah S. Self-care behaviors and related factors in women with type 2 diabetes. IJEM 2015; 16(6): 393-401.

19. Mazlom SR, Firooz M, Hoseini SJ, et al. Self-care of patient with diabetes type II. J Sabzevar Univ Med Sci 2016; 22(6): 1018-1015.

20. Parham M, Riahin A, Jandaghi M, et al. Self care behaviors of diabetic patients in Qom. Qom Uni Med Sci J 2013; 4(6): 81-87.

21. Cooper H, Booth K, Gill G. Patients' perspectives on diabetes health care education. Health Educ Res 2003; 18(2): 191-206.

22. Gillibrand R, Stevenson J. The extended health belief model applied to the experience of diabetes in young people. Br J Health Psychol 2006; 11(Pt. 1): 155-169.

23. Heidari S, NooriTajer M, Shirazi F, et al. Relationship between family support and glycemic control in patients with type-2 diabetes. Iran J Diabetes Lipid Disord 2008; 8: 93-102.

24. Morovati Sharifabad MA, Rouhani Tonekaboni N. Social support and self-care behaviors in diabetic patients referring to Yazd Diabetes Research Center. Zahedan J Res Med Sci 2008; 9(4): 275-284.

25. Asadi N, Royani Z. Assessing the relation between social support and depression among patients undergoing hemodialysis in Kerman City. J Hosp 2015; 14(2): 79-85.

26. Zare Shahabadi A, Hajizade Meimandi M, Ebrahimi Sadrabadi F. Influence of social support on treatment of type II diabetes in Yazd. SSU Journals 2010; 18(3): 277-283.

27. Aalto AM, Uutela A. Glycemic control, self-care behaviors, and psychosocial factors among insulin treated diabetics: a test of an extended health belief model. Int J Behav Med 1997; 4(3): 191-214.

28. SharifiradGR, Entezari MS, KamranA, etal. Effectiveness of nutrition education to patients with type 2 diabetes: the health beliefmodel. Iran J Diabetes Lipid Disord 2009; 7(4): 379-386.

29. Gleeson-Kreig J, Bernal H, Woolley S. The role of social support in the self-management of diabetes mellitus among a Hispanic population. Public Health Nurs 2002; 19(3): 215-222.

30. Wen LK, Shepherd MD, Parchman ML. Family support, diet, and exercise among older Mexican Americans with type 2 diabetes. Diabetes Educ 2004; 30(6): 980-993.

31. Marzilli G, Cossege W. The effects of social support on eating behavior in patient's whit diabetes 2005 [cited 5.05.2005]. Available from URL: http://insulin-pumpers.org/textlib/psyc353.pdf/.

32. Klomegah RY. The social side of diabetes: the influence of social support on the dietary regimen of people with diabetes. Sociation Today 2006; 4(2): 534-553.

33. Lloyd CE, Wing RR, Orchard TJ, et al. Psychosocial correlates of glycemic control: the Pittsburgh Epidemiology of Diabetes Complications (EDC) Study. Diabetes Res Clin Pract 1993; 21(2-3): 187-195.

34. Robat Sarpooshi D, Taghipour A, Mahdizadeh M, et al. Enablers of and barriers to effective diabetes self-care in Iran: a qualitative study. Patient Relat Outcome Meas 2020; 11: 109-118, doi: 10.2147/PROM.S241170.

35. Mayberry LS, Osborn CY. Family support, medication adherence, and glycemic control among adults with type 2 diabetes. Diabetes Care 2012; 35: 1239-1245.

Tables: 4

Figures: 0

References: 35

Received: 5.01.2020

Reviewed: 13.02 .2020

Accepted: 28.05.2020

Address for correspondence:

Nooshin Peyman, PhD

Social Determinants of Health Research Center

Mashhad University of Medical Sciences

Mashhad

Iran

Tel.: +98513 8544643

E-mail: nooshin.peyman@yandex.com 